\title{
DA CRISTIANIZAÇÃO DOS REINOS GERMÂNICOS À UNIÃO EUROPEIA DE ROBERT SCHUMANN: Um estudo sobre os principais alemães durante a história da Filosofia e a relação com o Cristianismo - Um estudo em Gramsci sobre o "eclesiástico orgânico"
}

\author{
André da Silva Barros ${ }^{1}$ \\ Universidade Federal de São Carlos - Sorocaba \\ andre_sbarros@hotmail.com
}

\section{RESUMO:}

O presente texto é fruto da pesquisa sobre a influência da religião, principalmente do Protestantismo, sobre a formação de um país europeu, unificado recentemente: a Alemanha. $\mathrm{Na}$ pesquisa, pode ser visto que a formação da consciência e da fé foi necessária para o desenvolvimento político dos reinos alemães desde Wulfila, o apóstolo dos godos, Clóvis e Carlos Magno, os reis cristãos de origem franca, sendo que Carlos é considerado o primeiro sacro imperador romano da nação alemã, o reino da Prußia, o filósofo e teólogo Lutero e a reforma religiosa, Otto von Bismarck, Hitler até chegar aos nossos dias com Robert Schuman, político e advogado, responsável pela unificação econômica da Europa. Como orientação filosófica, no século XII, data que se costuma introduzir os alemães na Filosofia, com Alberto Magno, indo até hoje com Habermas e Ratzinger, passando pelos escolásticos, protestantes, iluministas, românticos, idealistas, materialistas e filósofos contemporâneos. Estes pensadores discutiram sobre religião e o pensamento deles foi fundamental para a composição do Geist e do nacionalismo alemão. Assim que a idéia desse texto é compreender como a religião teve papel fundamental na formação desses Estados, uma vez que a fé se constitui como elemento importante da formação do indivíduo e da sociedade ao qual ele está inserido.

Palavras-chave: Filosofia alemã. Universidade Protestante. Eclesiástico Orgânico.

\section{Introdução:}

"Cabe à filosofia transformar a realidade". Para Marx, é preciso refletir, mas também agir. Para Gramsci, deve-se aplicar a teoria à prática, a reflexão na ação ("filosofia da praxis"). Cabe aos intelectuais orgânicos elaborar o desenvolvimento progressivo da sociedade. (GRAMSCI, 2001, p. 16). O eclesiástico é um intelectual tradicional que monopolizou a "ideologia religiosa, isto é, a filosofia e a ciência da época, com a escola." Então, um eclesiástico orgânico seria um religioso preocupado com as questões sociais de seu tempo, pensando na Igreja como formação de luta e de conquista sociais, políticas, econômicas, culturais, sem abandonar sua fé. É o pastor que sente o povo e aproveita os ensinamentos da igreja para buscar soluções sobre conflitos de gênero, de raça, de classes etc.

A Igreja pediu perdão, no ano 2000, Ano do Jubileu, sobre sua ação nos dois milênios do Cristianismo (BARROS, 2014a, p. 6). Essa reflexão mudou o pensamento da Igreja atual (como a Teologia da Libertação). Gramsci identificou de intelectual tradicional o

\footnotetext{
${ }^{1}$ Licenciado em Teatro/Arte-Educação, Filosofia e Pedagogia, pós-graduado em Ensino de Arte no Brasil e Teologia e é mestrando em Educação - Formação de Professores e Práticas Educativas na UFSCar Sorocaba. É docente de Arte, Filosofia e Sociologia na Educação Básica e presbítero da Igreja Evangélica Assembleia de Deus com ênfase no ensino da Escola Bíblica Dominical.
} 
clero católico de sua época e talvez caracterizasse diferentemente os clérigos que têm compromisso com a luta do povo por uma sociedade mais justa e fraterna. No entanto, em vários momentos, a Filosofia e a Teologia foram utilizadas com fins políticos. Wulfila, Clóvis e Carlos Magno (o primeiro sacro imperador germânico ${ }^{2}$ ) unificariam reinos através delas. Outros alemães criaram novas religiões, valorizando o trabalho e criaram universidades para divulgá-lo, recebendo alunos evangélicos destinados ao sacerdócio (Kant, Hegel e Nietzsche).

\section{Marx e Engels relacionam a ideologia alemã com o império romano}

Os homens fazem a história na medida em que devem produzir as suas vidas, e devem fazê-la de forma determinada. (MARX \& ENGELS, 2010, p. 56) O homem possui espírito e este se materializa em forma de consciência. Quando há a separação entre trabalho material e espiritual, surge a primeira forma dos ideólogos, os sacerdotes. (op. cit., p. 57):

A expressão idealista dos limites econômicos existentes não é puramente teórica, mas existe na consciência prática, [...] que se emancipa e está em contradição com o modo de produção existente. Não constitui somente religiões e filosofias, mas também Estados. (id ibidem, p. 58)

\section{As referências bíblicas sobre a Alemanha}

Moisés (Gênesis 10:3) escreveu, em 1450 a.C. (BÍBLIA, 1995, p. 2), sobre Asquenaz. Ashkenazi (nome hebreu para a Alemanha) refere-se ao bisneto de Noé, cuja descendência teria caminhado pela Armênia até a Europa. Este nome foi dado às comunidades judaicas da Alemanha, supondo que os israelitas conheciam a região. Gômer e Togarma também se relacionam à Germânia. Em Ezequiel cap. 37, os ossos de Israel se juntariam novamente, o que aconteceu em 1948. Gômer, (Ez. 38:5) procuraria exterminar os judeus com o auxílio de outras nações. Isso infelizmente ocorreu na Segunda Guerra.

O apóstolo Paulo diz que "não há grego, nem judeu, [...], bárbaro, cita, servo ou livre.” (Col. 3:11). Para Roma, o bárbaro é o germânico. Tácito (2006, II) escreveu em 98:

\footnotetext{
Celebram em antigos cânticos, que é a única maneira entre eles de recordar os anais do deus Tristão (Tuistoenem, donde deutsch) fautor da terra. E a Mano seu filho, origem e condutor do povo, atribuem-lhe três filhos [...] Itgo, Ermn e Isto, que são [...] os sobrenomes dos três deuses Freyr, Tin e Wodan.
}

A mitologia germânica renasceria no Sturm und Drang e no Romantismo, por Herder, Goethe, Schiller, Mozart, Grimm, Wagner e Nietzsche, exaltando seu nacionalismo.

\section{O pensamento teológico na História e na Filosofia alemã:}

\footnotetext{
${ }^{2}$ O Sacro Império Romano da Nação Alemã foi até 1806, sob as conquistas napoleônicas.
} 
O Cristianismo (preservado pelos romanos eclesiásticos após a queda do Império) influenciou a história dos vários reinos e impérios germânicos (Germânia, Frância Oriental, Sacro Império Romano-Germânico, Prußia, Alemanha). Segundo Gramsci (2001, p. 25,6):

Esta separação [entre os orgânicos $e$ os tradicionais] não apenas social, mas nacional, racial, entre grandes massas de intelectuais e a classe dominante do Império Romano se reproduz, após a queda do Império, entre guerreiros germânicos e intelectuais originários romanizados, continuadores da categoria dos libertos. Articula-se com estes fenômenos o nascimento e desenvolvimento do catolicismo e da organização eclesiástica que, por muitos séculos, absorveu a maior parte das atividades intelectuais e exerceu o monopólio da direção cultural, com sanções penais para quem quisesse se opor, ou mesmo ignorar, tal monopólio.

O primeiro teológo foi Wulfila (século IV), traduzindo a Bíblia ariana para o gótico:

A tradução foi fundamental para o entendimento do estado primitivo comum das línguas germânicas. Como os germanos não tinham literatura escrita antes da conversão ao Cristianismo (à exceção das runas), os estudos sobre a língua gótica são amplamente baseados nas manifestações literárias. (CARCASSE, 2014).

O rei Clóvis, em 481, unificaria os bárbaros, convertendo-se ao catolicismo:

Clóvis, um príncipe merovíngio, conseguiu ser aceito como governante dos francos orientais e ocidentais. Casou-se (tradicionalmente, em 496) com uma princesa católica da Borgonha, e depois, num campo de batalha, se converteu ao cristianismo, mais ou menos como acontecera com Constantino, o que lhe conferiu o apoio da Igreja gaulesa e do Papa. Com isto ele prosseguiu, conquistando o domínio de toda a Gália contra visigodos e borgonheses. Deslocou a capital para uma pequena cidade numa ilha do Sena que os romanos chamava de Lutécia. Seus habitantes eram cristãos (ali havia bispos, pelo menos desde 250 d.C.) e conhecidos como parisii e agora a cidade se chama Paris. Clóvis foi eventualmente sepultado ali como cristão, o primeiro rei franco a ser sepultado como tal. Quando ele morreu, suas terras foram divididas de acordo com os costumes francos. (ROBERTS, 2001, p. 347).

Vieram os ostrogodos (493 a 553), os longobardos (568 a 774) e o Sacro Império:

O "latim médio", portanto, ocuparia cerca de um milênio, entre a metade do século IV e o fim do século XIV, entre o início da inspiração cristã e a difusão do Humanismo. (GRAMSCI, 2001, p. 83)

Em 756, "seguiu-se a reforma da Igreja franca e ainda a colonização e a conversão da Alemanha por meio de guerras contra os saxões pagãos.” (ROBERTS, 2001, p. 348). Carlos Magno lutou "para se transformar de guerreiro no governante de um grande império cristão, e obtendo notável sucesso [...] Carlos Magno deu nova majestade à realeza germânica." (op. cit., p. 351). No entanto, a sucessão começaria com 962, com o otoniano de Heinrich I:

Com os carolíngios aliados ao papado, é concebida a monarquia universal abrangendo toda a humanidade, dirigida de comum acordo pelo imperador no plano temporal e pelo papa no espiritual. Mas esta concepção não podia delimitar o campo submetido a cada autoridade, deixando ao imperador uma larga margem de intervenção nas questões eclesiásticas. Quando as finalidades do Império, já sob os próprios carolíngios [...], revelaram-se em discordância com as da Igreja e o Estado revelou tender à absorção da hierarquia eclesiástica no Estado, começou a luta que se concluiu no princípio do século XII com a vitória do papado. Foi proclamada a 
primazia do espiritual (sol-lua) e a Igreja readquiriu a liberdade para sua ação legislativa, etc., etc. Esta concepção teocrática foi combatida teórica e praticamente, mas se manteve dominante, em sua forma genuína ou atenuada, durante séculos e séculos. Deste modo, havia dois tribunais, o sacramental e o não-sacramental; deste modo, os dois direitos foram acoplados. (GRAMSCI, 2001, p. 89)

Aliás, existiram oito papa alemães: o ostrogodo Bonifácio II (530-532), a teutônica Joana (entre 850 e 858), Estêvão VII (929-931) e Gregório V (996-999). O rei Heinrich III nomeou o saxão Clemente II (1046-47), o bávaro Dâmaso II (1048) e Vítor II (1055-57). O último foi Joseph Ratzinger (2005-2013). Os doutores da Igreja são dois: Hildegarda (10981179) e Alberto Magno (1206-1280). Alberto é o primeiro filósofo alemão nas listas de Filosofia, seguido de Eckardt (1260-1327), Agrippa (1485-1535) e Nicolau de Cusa (14011464). Neste tempo aparece o homem que, segundo muitos, é o mais importante da história:

Em 1456, [...] Johann Gutenberg publicou a primeira edição da Bíblia produzida pelo novo sistema - a chamada "Bíblia de 42 linhas" [...]. Em poucas décadas, havia prensas em operação por toda a Europa. Em 1465, o homem que passara seus primeiros anos escapando de processos na Justiça recebeu várias homenagens devido ao seu trabalho sobre o arcebispo Adolf, de Mainz. (YENNE, 2002, p. 82)

\section{O protestantismo}

Abrão (1999, p. 171) nos traz o contexto social da Europa do século XVI:

Mergulhada em discussões teológicas, em cerimônias complexas e ostentatórias, em exemplos de vida nada edificantes, cada vez mais afastada do povo, a Igreja perde o rumo. Já não controlava mais os reis [e] os fiéis aderem a movimentos reformadores que pregam a desobediência (ABRÃO, 1999, p. 171)

Enquanto que os reformadores romperam com o Catolicismo (Jan Huss, Henrique VIII e Wyclif), buscando reformar o papel social da Igreja, outros se preocupavam com a formação nacional e a abertura da participação política:

Não [...] devemos ter a esperança de encontrar nos fundadores ou nos representantes de tais movimentos religiosos os promotores daquilo que chamamos de espírito do capitalismo, com o sentido de finalidade de vida. [...].A salvação da alma, e só ela era o centro de seu trabalho e de suas vidas. (WEBER, 2004, p. 74).

A reforma religiosa veio na Alemanha, com Martinho Lutero:

A Alemanha é um palco propício para a propagação das idéias de Lutero. [...] ela é um mosaico de Estados e cidades que buscam afirmar sua soberania. Isso se traduz também nos anseios de rompimento com o papado, que cobra cada vez mais tributos desses Estados. Neles, têm nos anseios de rompimento com o papado, que cobra cada vez mais tributos desses Estados. Neles, os cavaleiros (representantes da pequena nobreza) opõem-se aos grandes proprietários, cuja maioria é formada por membros da Igreja. (ABRÃO, 1999, p. 174)

Vinte e nove anos após a morte de Lutero, a semente de transformação da sociedade alemã através desta nova forma de religião germinaria em seu país: 
Quando Lutero morre, em 1546, sua doutrina já havia conquistado grande parte da Alemanha. O ponto de partida dessa difusão foi a desobediência, em 1529, de seis príncipes e catorze cidades alemães, que protestaram (daí o nome protestantes) contra a decisão do Império de reiterar o banimento de Lutero. A aliança entre príncipes e Lutero estava selada. (id ibidem, p. 176)

A diferença entre os países protestantes e católicos, é que a nova religião permitia o trabalho e a acumulação de riquezas. Sob essa ética, o Calvinismo já pregava:

Cada homem deve executar seus afazeres - não apenas os religiosos - de modo laborioso, para a glória de Deus, de quem é um instrumento [...] Para Calvino, isso deve ser sinal de que o bem-sucedido é um dos eleitos, pois é por intermédio destes que Deus se glorifica melhor [...] a doutrina de Calvino seria entendida como permissão para a busca da riqueza, em nome da glória de Deus. Esse dado, juntamente com a restrição ao consumo, levaria à acumulação capitalista [...], que já se insinuava nas entrelinhas do calvinismo e de outras doutrinas protestantes. (ABRÃO, 1999, p. 180,1)

Weber (2004) cita um escritor que fala da relação capitalismo-protestantismo:

O católico é mais quieto, tem menor impulso aquisitivo; prefere uma vida mais segura $[\ldots]$, mesmo tendo menores rendimentos, a uma vida mais excitante e cheia de riscos, mesmo que esta possa lhe propiciar a oportunidade de ganhar honrarias e riquezas. Diz o provérbio, jocosamente: "Coma ou durma bem". [...], o protestante prefere comer bem, e o católico, dormir sossegado. (WEBER, 2004, p. 40,1)

Weber (op. cit., p. 70) diz que "o efeito da Reforma foi o de aumentar poderosamente a ênfase moral e a sanção religiosa em relação ao trabalho secular organizado no âmbito da vocação.” No entanto, a preocupação de Lutero não era econômica, mas teológica.

\section{A Alemanha de Bismarck: Kulturkampf e o império alemão}

Na Rheinbund (napoleônica), nas Confederações Renana, Germânica e da Alemanha do Norte, no Império Alemão (ou segundo Reich), na República de Weimar, na Alemanha Nazi (ou terceiro Reich), nas duas Alemanhas e na reunificação em 1990:

[O industrialismo moderno] manifestou-se também na Alemanha, complicado aqui por outros elementos históricos e tradicionais. A Alemanha, como a Itália, foi a sede de uma instituição e de uma ideologia universalista, supranacional (Sacro Império Romano da Nação Alemã), [...] Os junker prussianos assemelham-se a uma casta sacerdotal-militar, que possui um quase monopólio das funções diretivoorganizativas na sociedade política. (GRAMSCI, 2001, p. 28,9)

Logo, com a Prußia protestante, muito mais do que o uso da fé, sobressaía o uso político. A unificação alemã ocorrera em 1871, pelas mãos de Bismarck. Preocupado, no entanto, com o aspecto cultural, artístico e religioso da nova nação, ele instala o Kulturkampf:

Com Kulturkampf, Gramsci refere-se provavelmente ao movimento empreendido por Otto von Bismarck, entre 1872 e 1875, quando - em seu empenho pela constituição da unidade estatal alemã - o chanceler do Reich se opôs duramente ao Centro, partido católico de massa de tipo confessional. (GRAMSCI, 2001, p. 292) 
Proudhon (GRAMSCI, 2001, p. 183), ao buscar uma reforma na França:

[...] parece estar convencido de que é necessária uma reforma intelectual em sentido laico ("filosófico"), mas não sabe encontrar outro meio didático além da mediação do clero. [...] o modelo é o protestante, isto é, a reforma intelectual e moral ocorrida na Alemanha com o protestantismo. (id ibidem, p. 292)

\section{A universidade iluminista e alguns filósofos protestantes}

Na Alemanha, marcada pelo protestantismo, as Luzes não se voltam contra a Igreja, mas procuram verificar se a razão e a revelação são incompatíveis, como afirmava Lutero. (ABRÃO, 1999, p. 305)

No Sacro Império, foram construídas universidades em Marburg; Königsberg, Jena Strassburg, Helmstedt, Altdorf, Giessen Rinteln e Kassel. (MAINKA, 2014, p. 6). Seus primeiros alunos foram Althusius, Boehme, Wolff e Leibniz, que se interessava por filosofia, matemática, direito, questões religiosas e política, influenciando Kant, Hegel e a filosofia contemporânea. No século XVIII, se na França, os iluministas foram os responsáveis pela Revolução, a Alemanha não viveu uma revolução. Segundo Hegel, "o protestantismo já havia conciliado a liberdade interior com o mundo exterior." (ABRÃO, 1999, p. 297)

Araújo (2011) biografa dez filósofos que pensaram a universidade iluminista. Nove deles são alemães: Kant, para quem "a teologia é uma estrutura de poder que intervém nos rumos do Estado" (p. 46), Schelling, "estudou no seminário teológico de Tübingen” (p. 56), Fichte, que defendia "na Alemanha, a reformulação da escola elementar (cujas tradições remontavam a Lutero)" (p. 84), Schleiermacher ${ }^{3}$, que escreveu Sobre a religião, Sermões, A fé cristã segundo os princípios da Igreja Evangélica, Hermenêutica, Hegel, que "ingressou no seminário de teologia protestante de Tübingen [...] Rompeu com o plano de ser pastor por entender que não tinha vocação para tal." (p. 127), Humboldt que "foi convidado a dirigir o departamento de Ensino e Cultos do ministério do Interior prußiano, [...] com temáticas relacionadas às Igrejas.” (p. 154), Nietzsche (1844-1900), cujo pai e avós eram pastores protestantes; [...] seus colegas de escola o chamavam de "pequeno pastor". (CHAUÍ, 2005, p. 5), Max Weber, de mãe protestante, pode se enveredar nos estudos de história, economia, filosofia e teologia. (WEBER, 2004, p. 15) e Scheler (1874-1928), um pensador católico.

\section{A Contemporaneidade}

\footnotetext{
${ }^{3}$ Seu pai era pastor protestante. [...] estudou filosofia, teologia e filologia. Ordenou-se pastor em 1794. Por dois anos foi pregador auxiliar em Landsberg. Em Berlim, foi pastor entre 1796 e 1802, foi aí que publicou, sob pseudônimo, a obra, Sobre a religião. Posteriormente foi professor de Teologia em Halle. (op. cit., p. 102)
} 
Adota-se o termo filosofia contemporânea o período que se estende de meados do século XIX até aos dias atuais. Chauí (2010, p. 58-67) destaca enquanto aspectos da Filosofia Contemporânea, que os problemas filosóficos seriam história e progresso, as ciências e as técnicas, os ideais políticos revolucionários, o fim da filosofia (Husserl), a maioridade da razão (Marx), o infinito e o finito, (pós-hegelianos), os nossos dias: a pós-modernidade (Nietzsche) e temas, disciplinas e campos filosóficos (Kant) nazismo e Segunda Grande Guerra. É perceptível a influência alemã sobre esses temas. É o período de Wittgenstein, Horkheimer, Benjamim, Adorno, Bohr, Heisenberg, Breuer, Cohen, Bolzano, Brentano, Husserl, Heidegger, Rosenzweig, Popper, Apel, Habermas e Ratzinger, o papa Bento XVI. Os dois últimos escreveram em conjunto as obras A dialética da secularização: na razão e na religião, porém, o conflito filosófico entre eles ficou conhecido como o Cisma do século XXI. O último alemão a ser citado nesta pesquisa é aquele que conseguiu unificar a Europa economicamente e que reservou em seu plano o "reconhecimento da identidade [religiosa] e o seu contributo específico, a União mantém um diálogo aberto, transparente e regular com as referidas igrejas e organizações” (JORNAL OFICIAL DA UNIÃO EUROPEIA, 2014):

\begin{abstract}
Robert Schuman ${ }^{4}$, político, advogado de alto nível e Ministro dos Negócios Estrangeiros francês entre 1948 e 1952, é considerado um dos promotores da unificação europeia. Nascido no Luxemburgo e influenciado pela sua origem na fronteira entre a França e a Alemanha, Robert Schuman, apesar das experiências vividas na Alemanha nazi [...], compreendeu que só uma reconciliação duradoura entre a França e a Alemanha podia dar origem a uma Europa unida. [...] Schuman informou deste plano o Chanceler alemão Adenauer, que vendo nele imediatamente uma oportunidade para pacificar a Europa, o aprovou. (UNIÃO EUROPEIA, 2014)
\end{abstract}

Finalmente, a contribuição do pensamento filosófico alemão no Brasil,

[...] destacam-se as obras de Tobias Barreto e de Farias Brito, pela originalidade de pensamento e pelo nível de elaboração teórica, certamente superior aos demais. (JAPIASSU \& MARCONDES, 2006, p. 110)

Tobias Barreto (1839-1889) foi o filósofo que introduziu o pensamento alemão no Brasil. Sua "mania germânica" o fez escrever o jornal recifense Deutscher Kampfer, em 1882. Ao estudar os alemães, investigou se haveria uma nacionalidade brasileira. Também o primeiro material pedagógico trazido pelos jesuítas ao Brasil é a Ratio Studiorum. Nele, pedese que o professor (catequizador) ensine Aristóteles como conteúdo de Filosofia e Tomás de Aquino como Teologia. Ora, o italiano foi discípulo do grande filósofo alemão Albert der Große. Também é inquestionável a influência protestante no Brasil, o aumento da população evangélica no país e a quantidade de igrejas pentecostais que surgiram em solo tupiniquim.

\footnotetext{
${ }^{4}$ Estudou na Humboldt-Univeristät zu Berlin, bem como 29 contemplados com o Prêmio Nobel (Max Planck, Einstein, Heisenberg etc.), filósofos como Hegel, Schopenhauer, Karl Marx e Engels, além de Bismarck.
} 
"No Brasil [...] se unir todos os cristãos, tem-se $86 \%$ e unindo todas as igrejas evangélicas (as de missão e as pentecostais), tem-se 22\%.” (BARROS, 2014b, p. 13)

\section{Considerações Finais:}

A religião correspondeu ao propósito marxista de transformação. Isso foi possível porque eclesiásticos orgânicos utilizaram a fé e o pensamento para refletir sobre a sociedade e promover mudanças. Roma foi o berço, mas foi na Alemanha que a Igreja se desenvolveu.

É interessante observar como o discurso religioso é um instrumento de reforma, de união, de força, de simbologia que une um povo através da fé. Saber disso facilita o trabalho do filósofo e teólogo que comanda e conduz sua comunidade, estando à frente de seu povo, gerando ações heróicas, como foram as vezes que houve uma unificação alemã na história.

Os filósofos e teólogos alemães falaram sobre reformas sociais, sendo a universidade e a Igreja os espaços para a discussão desses problemas. Assim, enquanto professores e eclesiásticos orgânicos (conceito extraído de Gramsci), nossa função é olhar a sociedade e discuti-las na sala de aula e no interior das igrejas. Para Lutero, foi necessário expô-las na porta da catedral de Wittenberg. Hoje, há a possibilidade de discussão entre líderes espirituais e seus fiéis nos espaços religiosos, nas universidades, nas escolas e em outros ambientes.

\section{REFERÊNCIAS:}

ABRÃO, Bernadete Siqueira (Org.) História da filosofia. São Paulo: Nova Cultural, 1999.

ARAÚJO, José Carlos Souza (Org.) A universidade iluminista (1798 - 1921): de Kant a Scheler. Brasília, DF: Liber Livro, 2011.

BARROS, André da Silva A BÍBLIA COMO LITERATURA AFRICANA: O Discurso Religioso no Olhar da Igualdade Racial. II Congresso Nacional de Africanidades e Brasilidades (CONAB). Vitória, ES: UFES Goiabeiras, 2014a. ISBN: 978-85-99345-22-1.

Escola Bíblica Dominical e Escola de Domingo: um estudo em Engels sobre a Educação nos Movimentos Sociais Religiosos. II Congresso Nacional de Movimentos Sociais. Ilhéus, BA: UESC, 2014b.

BÍBLIA. Português. Bíblia de Estudo Pentecostal. ARC. Rio de Janeiro: CPAD, 1995.

CARCASSE. Os registros dos godos. Revista Pesadelar. Disponível em: http://www.carcasse.com/revista/pesadelar/os_registros_dos_godos/index.php. Acesso em: 10 ago. 2014.

CHAUÍ, Marilena de Souza; FEREZ, Olgária Chaim. Nietzsche. Vida e Obra. São Paulo: Nova Cultural, 2005. 
CHAUÍ, Marilena. Iniciação à filosofia: ensino médio, volume único. São Paulo: Ática, 2010.

FORBES. As The 25 Most Powerful Women In The World, 2014. Disponível em: http://www.forbes.com/sites/carolinehoward/2014/05/28/the-worlds-most-powerful-women2014/ Acesso em: 11 ago. 2014.

GRAMSCI, Antonio. Cadernos do cárcere, volume 2. $2^{\mathrm{a}}$ ed. - Rio de Janeiro: Civilização Brasileira, 2001.

JAPIASSU, Hilton; MARCONDES, Danilo. Dicionário Básico de Filosofia. 4 ed. atual. Rio de Janeiro: Jorge Zahar ed., 2006.

JORNAL OFICIAL DA UNIÃO EUROPEIA. C115/55 9.5.2008. Disponível em: http://eurlex.europa.eu/legal-content/PT/TXT/PDF/?uri=OJ:C:2008:115:FULL\&from=EN. Acesso em: 11 ago. 2014.

MAINKA, Peter Johann. A Reforma Protestante e as universidades alemãs continuidade e mudança da Idade Média aos tempos modernos (por volta de 1350 1648). Disponível em: http://www.sbhe.org.br/novo/congressos/cbhe1/anais/127_peter.pdf. Acesso em: 12 ago. 2014.

MARX, Karl; ENGELS, Friedrich. A Ideologia Alemã. $3^{\text {a }}$ reimpressão. São Paulo, SP: Martin Claret, 2010.

ROBERTS, J. M.. O Livro de Ouro da História do Mundo. 5 ed. tradução de Laura Alves e Aurélio Rebello. Rio de Janeiro: Ediouro, 2001.

TÁCITO, Públio Cornelio Germânia (trad. e notas de Sadi Garibaldi). Rio de Janeiro: Editora Livraria Para Todos, 1943.

UNIÃO EUROPEIA. Robert Schuman. Disponível em: http://europa.eu/about-eu/euhistory/1945-1959/foundingfathers/schuman/index_pt.htm Acesso em: 12 ago. 2014.

WEBER, Max. A Ética Protestante e o Espírito do Capitalismo. ed. revisada. São Paulo, SP: Martin Claret, 2004.

YENNE, Bill. 100 homens que mudaram a história do mundo. tradução de Roger Maiole. São Paulo: Ediouro, 2002. 